\title{
Highly Sensitive Near-Infrared SERS Nanoprobes for in Vivo Imaging Using Gold-Assembled Silica Nanoparticles with Controllable Nanogaps
}

\author{
Sungje Bock \\ Konkuk University \\ Yun-Sik Choi \\ Seoul National University \\ Minhee Kim \\ Konkuk University \\ Yewon Yun \\ Konkuk University \\ Xuan-Hung Pham \\ Konkuk University \\ Jaehi Kim \\ Konkuk University \\ Bomi Seong \\ Konkuk University \\ Wooyeon Kim \\ Konkuk University \\ Ahla Jo \\ Konkuk University \\ Kyeong-Min Ham \\ Konkuk University \\ Sung Gun Lee \\ Seoul National University
}

Sang Hun Lee

Hanbat National University

Homan Kang

Harvard Medical School

Hak Soo Choi

Harvard Medical School

Dae Hong Jeong

Seoul National University

Hyejin Chang 
Kangwon National University

\section{Dong-Eun Kim}

Konkuk University

\section{Bong-Hyun Jun ( $\sim$ bjun@konkuk.ac.kr )}

Konkuk University https://orcid.org/0000-0001-6556-7946

\section{Research Article}

Keywords: Surface enhanced Raman spectroscopy (SERS), gold nanoparticle, nanogap, hotspot, in vivo imaging.

Posted Date: December 16th, 2021

DOI: https://doi.org/10.21203/rs.3.rs-1133683/v1

License: (c) (i) This work is licensed under a Creative Commons Attribution 4.0 International License. Read Full License

Version of Record: A version of this preprint was published at Journal of Nanobiotechnology on March 12th, 2022. See the published version at https://doi.org/10.1186/s12951-022-01327-7. 


\section{Abstract \\ Backgroud:}

Surface-enhanced Raman scattering (SERS) imaging is widely exploited, given its advantages such as multiplex capacity, non-photobleaching property, and high sensitivity. Near-infrared (NIR) radiation is suitable for in vivo studies because it exhibits good tissue penetration capability.

\section{Results}

In this study, gold ( $\mathrm{Au})$-assembled silica $\left(\mathrm{SiO}_{2}\right)$ nanoparticles $\left(\mathrm{SiO}_{2} @ \mathrm{Au} @ A u\right.$ NPs$)$ as NIR SERS nanoprobes are synthesized by a seed-mediated growth method. $\mathrm{SiO}_{2} @ \mathrm{Au} @ A u$ NPs with six different sizes of Au NPs are prepared by controlling the concentration of the Au precursor in the growth step. Therefore, the surface plasmonic band of the nanogaps between Au NPs on the $\mathrm{SiO}_{2}$ surface could be controlled from 4.16 to 0.98 nm, thus generating SERS hotspots. $\mathrm{SiO}_{2} @ A u @ A u$ NPs with a 0.98-nm gap shows high SERS signals after being subjected to an excitation wavelength of $785 \mathrm{~nm}$ (enhancement factor 3.8 × 106 $)$. SiO $2 @ A u @ A u$ nanoprobes shows detectable in vivo SERS signals at a concentration of $16 \mu \mathrm{g} / \mathrm{mL}$ in a 7-mm-thick animal tissue specimen.SiO ${ }_{2} @ A u @ A u$ NPs with 14 different Raman label compounds shows distinguishable SERS signals upon being subcutaneously injected into nude mice.

\section{Conclusion}

Through this study, it is highlighted that their potential for use in in vivo applications as multiplex nanoprobes.

\section{Backgroud}

Near-infrared (NIR) light has attracted attention for in vivo molecular imaging, owing to its good penetration ability into tissues [1-3]. Multiplexing is imperative for in vivo molecular imaging to observe the simultaneous effects of different drugs and their multiple tumor targeting abilities [4]. However, some widely used materials with NIR activity, such as fluorescent dyes and up-conversion luminescent nanoparticles (NPs) $[5,6]$ still suffer from spectral overlaps, which results in the formation of a limited number of distinct NPs [7]. To overcome this limitation, surface-enhanced Raman spectroscopy (SERS)based detection of NIR active nanoprobes has been applied as a multiplex imaging tool, given the narrow bandwidth $(<2 \mathrm{~nm})$ of Raman signals [8-10]. SERS has been demonstrated as a powerful tool for biological and chemical analyses and imaging, owing to its high sensitivity, multiplexing ability, and selectivity [11-19].

Gold NPs (Au NPs) have been widely used in many bio-applications such as biosensing, imaging, and photothermal therapy (PTT) [20-27] based on the plasmon resonance phenomenon with visible and NIR 
radiations [28]. Various methods for the synthesis of Au NPs with well-controlled shapes and sizes have been reported to exploit their unique optical properties [29-31]. Au NPs have good biocompatibility and high stability compared to NPs of other metals under biological conditions [32-34]. In addition, their plasmonic feature, which is tunable up to the NIR region, is considered as one of the most valuable properties for in vivo SERS imaging. However, in comparison with silver (Ag) NPs, which provide better SERS enhancement owing to their strong surface plasmon resonance property [35], Au NPs have relatively weak signal enhancement ability. Thus, the weak signals from Au NPs pose difficulties in the analysis of deep tissues using an NIR SERS nanoprobe. Many researchers have studied effective Au nanostructures as SERS nanoprobes to overcome the limited SERS enhancement performance of Au NPS [36-38].

Wang et al. reported a seed-mediated growth method for Au nanostars, which exhibit strong absorbance in the NIR region, and showed the possibility of imaging and treating cancer cells through PTT [39]. Ding et al. reported sea urchin-like, flower-like, meatball-like, and polyhedral Au mesopores of various sizes and shapes [40]. Au NP-assembled nanostructures were found to exhibit strong SERS signals, generating multiple hotspots within the Au NP nanogap [41]. However, Au NP-assembled nanostructures that do not use seed-mediated growth methods may have shortcomings, including the difficulty in producing a uniform shape and controlling the nanogap and a long tedious synthesis process.

We recently prepared Au-assembled silica $\left(\mathrm{SiO}_{2}\right)$ NPs by finely controlling the size of Au NPs on the surface of $\mathrm{SiO}_{2} \mathrm{NPs}$ [42]. At present, there are no studies on the nanogaps between Au NPs and the characteristics of SERS, which can be critical for NIR SERS imaging. In the present study, Au NPassembled $\mathrm{SiO}_{2} \mathrm{NPs}\left(\mathrm{SiO}_{2} @ A u @ A u\right.$ NPs ) with small nanogaps were synthesized for the development of NIR SERS nanoprobes. Nanogaps serving as SERS hotspots were generated by controlling the degree of $\mathrm{Au}$ NP growth on the surface of $\mathrm{SiO}_{2}$ NPs. Our $\mathrm{SiO}_{2} @ A u @ A u$ NPs showed a single-particle level detection sensitivity after NIR photoexcitation with a 785-nm laser and were applied for in vitro imaging using the HCT 116 cell line. To evaluate their capability as SERS nanoprobes, SiO ${ }_{2} @ A u @ A u$ NPs labeled with 4fluorobenzenethiol (4-FBT) were investigated for signal penetration depth in porcine tissues and detectable concentration limit after subcutaneous injection.SiO ${ }_{2} @ A u @ A u$ NPs labeled with 14 types of Raman labeling compounds (RLCs) showed distinguishable Raman spectra, and had unique bands upon subcutaneous injection. The highly enhanced SERS signals and spectroscopic features of $\mathrm{SiO}_{2} @ \mathrm{Au} @ \mathrm{Au}$ NPs indicate that our NIR nanoprobe has the potential for use in multiplexing imaging with various RLCs in vivo.

\section{Materials And Methods}

\section{Materials}

Tetraethyl orthosilicate (TEOS), (3-aminopropyl)triethoxysilane (APTS), tetrakis(hydroxymethyl)phosphonium chloride (THPC), polyvinylpyrrolidone (PVP), gold (III) chloride trihydrate $\left(\mathrm{HAuCl}_{4}\right)$, ascorbic acid (AA), Paraformaldehyde, 4-fluorobenzenethiol (4-FBT), 2- 
naphthalenethiol (2-NT), 3,5-dichlorobenzenethiol (3,5-DCT), 4-chlorobenzenethiol (4-CBT), 4methylbenzenethiol (4-MBT), 4-mercaptophenol (4-MP), 4-bromobenzenethiol (4-BBT), 4-aminothiophenol (4-ATP), 4-mercaptobenzoic acid (4-MBA), 4-mercaptophenyl boronic acid (4-MPBA), benzenethiol (BT), 2bromobenzenethiol (2-BBT), 3,4-dichlorobenzenethiol (3,4-DCT), and 2-fluorobenzenethiol (2-FBT) were purchased form Sigma-Aldrich (St. Louis, MO, USA). Ethanol (EtOH) and aqueous ammonium hydroxide $\left(\mathrm{NH}_{4} \mathrm{OH}\right)$ were purchased form Daejung (Sihung-si, Gyeonggi-do South Korea). Sodium hydroxide $(\mathrm{NaOH})$ was purchased from Samchun (Pyeongtaek-si, Gyeonggi-do, South Korea). Deionized water (DW) was produced by a Millipore water purification system of Vivagen (Seongnam-si, Gyeonggi-do, South Korea). HCT 116 cells were purchased from American Type Culture Collection (ATCC) (Manassas, VA, USA). RPMI 1640 was purchased from Biowest (Riverside, MO, USA). Fetal bovine serum (FBS) was purchased from JCBIO (Seoul, South Korea). Penicillin streptomycin was purchased from Welgene (Gyeongsan-si, Gyeongsangbuk-do, South Korea). Phosphate-buffered saline (PBS) was purchased from BYLABS (Hanam-si, Gyeonggi-do, South Korea). Sodium dodecyl sulphate (SDS) was purchased from LPS solution (Daejeon-si, South Korea). Eight-weeks-old female Balb/c athymic nude mice were purchased from Orient Bio Inc. (Seongnam-si, Gyeonggi-do, Korea).

\section{Preparation of SiO ${ }_{2} @ A u @ A u$}

$\mathrm{SiO}_{2} @ \mathrm{Au}$ was synthesized using a previously reported method [42]. Briefly, Au NPs (3 nm) were prepared using the Turkevich method. To obtain $3 \mathrm{~nm}$ Au NPs, $1.5 \mathrm{~mL}$ of sodium hydroxide $(\mathrm{NaOH} ; 0.2$ M), $12 \mu \mathrm{L}$ of THPC, and $1.5 \mathrm{~mL}$ of chloroauric acid $\left(\mathrm{HAuCl}_{4}\right)$ solution $(50 \mathrm{mM})$ were added to $47.5 \mathrm{~mL}$ of distilled water $(\mathrm{DW})$. The mixture was vigorously stirred for $1 \mathrm{~h}$ and stored in a refrigerator for at least 2 days. In addition, $62 \mu \mathrm{L}$ of APTS and $40 \mu \mathrm{L}$ of ammonium hydroxide $\left(\mathrm{NH}_{4} \mathrm{OH}\right)$ were added to $1 \mathrm{~mL}$ of $\mathrm{SiO}_{2} \mathrm{NPs}(50 \mathrm{mg} / \mathrm{mL}$ ), and the mixture was stirred at $700 \mathrm{rpm}$ for overnight to produce aminated $\mathrm{SiO}_{2} \mathrm{NPs}$. Then, the $\mathrm{SiO}_{2}-\mathrm{NH}_{2} \mathrm{NPs}$ were washed several times with ethanol via centrifugation, and $10 \mathrm{~mL}$ of $\mathrm{Au}$ NPs and $200 \mu \mathrm{L}$ of $\mathrm{SiO}_{2}-\mathrm{NH}_{2} \mathrm{NPs}(10 \mathrm{mg} / \mathrm{mL})$ were mixed and stirred for overnight. $\mathrm{SiO}_{2} @ A u$ NPs were obtained after washing several times with ethanol via centrifugation. These $\mathrm{SiO}_{2} @ A$ Au NPs were dispersed in $2 \mathrm{~mL}$ of DW containing $2 \mathrm{mg}$ of PVP.

$\mathrm{SiO}_{2} @ \mathrm{Au} @ \mathrm{Au}$ NPs were prepared as per the method described by our group [42] with some modifications. Briefly, $\mathrm{SiO}_{2} @ A u @ A u$ NPs were synthesized according to the seed-mediated growth method using $\mathrm{SiO}_{2} @ A u$ NP seed and Au precursor. To grow Au into the $\mathrm{SiO}_{2} @ A u$ seed, $200 \mu \mathrm{L}$ of $\mathrm{SiO}_{2} @$ Au NPs $(1 \mathrm{mg} / \mathrm{mL}$ ) were dispersed in $9.8 \mathrm{~mL}$ DW containing $10 \mathrm{mg}$ of PVP. This suspension was stirred with $20 \mu \mathrm{L}$ of $\mathrm{HAuCl}_{4}(10 \mathrm{mM})$, and treated with $40 \mu \mathrm{L}$ of $\mathrm{AA}(10 \mathrm{mM})$ every 5 min until the desired concentration of $\mathrm{Au}^{3+}$ was achieved $(50,100,200,300,400$, and $500 \mu \mathrm{M})$.Then, SiO ${ }_{2} @ A u @ A u$ was obtained after washing several times with ethanol via centrifugation.

\section{Labelling $\mathrm{SiO}_{2} @ A u @ A u$ with Raman chemical}


An RLC solution (2 mM) was prepared and added to $1 \mathrm{~mL}$ of $\mathrm{SiO}_{2} @ A u @ A u$ NPs $(1 \mathrm{mg} / \mathrm{mL})$. The mixture was vigorously shaken for $1 \mathrm{~h}$ at $25{ }^{\circ} \mathrm{C}$, and the RLC-conjugated $\mathrm{SiO}_{2} @ A u @ A u$ obtained was washed several times with ethanol via centrifugation. Subsequently, Raman-labeled $\mathrm{SiO}_{2} @ A u @ A u$ $\left(\mathrm{SiO}_{2} @ \mathrm{Au} @ \mathrm{Au}_{\mathrm{RLC}}\right) \mathrm{NPs}$ were redispersed in $1 \mathrm{~mL}$ of ethanol.

\section{SERS measurement for $\mathrm{SiO}_{2} @ A u @ A u_{\mathrm{RLC}}$}

$\mathrm{SiO}_{2} @ A u @ A u_{\mathrm{RLC}}$ suspensions $(1 \mathrm{mg} / \mathrm{mL})$ were injected into a capillary tube. The SERS spectra of each NP were measured thrice using a microscopic Raman system. Measurement was carried out using 532$\mathrm{nm}$ photoexcitation at $1 \mathrm{~mW}, 660-\mathrm{nm}$ photoexcitation at $1.2 \mathrm{~mW}$, and $785-\mathrm{nm}$ photoexcitation at $2.1 \mathrm{~mW}$ laser power, and a $\times 10$ objective lens with a 5 -s acquisition time.

\section{Calculation of SERS enhancement factor (EF)}

The SERS EF of $\mathrm{SiO}_{2} @ A u @ \mathrm{Au}_{4-\mathrm{FBT}}$ (with $500 \mu \mathrm{M}$ of Au precursor) at $785 \mathrm{~nm}$ photoexcitation was estimated using the following equation: $\mathrm{EF}=\left(\mathrm{I}_{\text {SERS }} \times \mathrm{N}_{\text {normal }}\right) /\left(\mathrm{I}_{\text {normal }} \times \mathrm{N}_{\mathrm{SERS}}\right)$ where $\mathrm{I}_{\mathrm{SERS}}$ and $\mathrm{I}_{\text {normal }}$ indicate the intensity of the Raman band from SERS and normal Raman, respectively, and $N_{\text {normal }}$ and $\mathrm{N}_{\mathrm{SERS}}$ are the number of 4-FBT molecules in the pure form and assembled form, respectively, on the surface of $\mathrm{SiO}_{2} @ A u @ A u_{4-F B T}$ NPs. Raman signal intensity was measured for both pure 4-FBT and single particles using an identical $\times 100$ objective lens under the following conditions: $0.3 \mathrm{~mW}$ laser power and 5 s acquisition time. The 4-FBT peak at $1075 \mathrm{~cm}^{-1}$ was used to estimate EF. I I ers were obtained by averaging the peak intensities of 20 individual particles. The probing volume $\left(18.84 \mu \mathrm{m}^{2}\right)$ for the normal Raman measurement was approximated by a cylindrical form with a diameter of $2 \mu \mathrm{m}$ and height of 6 $\mu \mathrm{m}$. Assuming that 4-FBT molecules form a monolayer on the surface of the NP, $\mathrm{N}_{\text {SERS }}$ was calculated from the surface area of the NPs (assuming that $\mathrm{SiO}_{2} @ A u @ \mathrm{Au}_{4-\mathrm{FBT}}$ has a spherical shape, $\mathrm{r}=115 \mathrm{~nm}$ ) and the molecular footprint of 4-FBT $\left(0.383 \mathrm{~nm}^{2} /\right.$ molecule) [43].

\section{Cytotoxicity of $\mathrm{SiO}_{2} @ A u @ A u_{4-F B T}$ to HCT 116 cells}

HCT 116 cells (human colon cancer cell line) were cultured in Roswell Park Memorial Institute (RPMI)-1640 medium with 10\% heat-inactivated fetal bovine serum (FBS) and 1\% penicillin/streptomycin at $37^{\circ} \mathrm{C}$ in humidified air with $5 \% \mathrm{CO}_{2}$. Cytotoxicity tests of NPs were conducted using a crystal violet assay. Cells were seeded in 96-well plates and incubated with different concentrations $(0,1.95,3.90,7.81$, $15.63,31.25$, and $62.50 \mathrm{mg} / \mathrm{mL}$ ) of $\mathrm{SiO}_{2} @ A u @ A u_{4-\mathrm{FBT}} \mathrm{NPs}$ at $37^{\circ} \mathrm{C}$ for $24 \mathrm{~h}$. After incubation, the culture medium was removed and the cells were fixed with $4 \%$ paraformaldehyde for $1 \mathrm{~h}$. Then, the cells were washed with DW and air-dried. The cells in each well were treated with $100 \mu \mathrm{L}$ of a $0.5 \%$ crystal violet solution. After 10 min, the solution was removed, and the plates were washed with DW and air-dried. Subsequently, the cells were lysed with $1 \%$ sodium dodecyl sulfate (SDS), and the absorbance was measured using a VICTOR X3 multilabel plate reader (PerkinElmer, Waltham, MA, USA) at $570 \mathrm{~nm}$.

\section{SERS imaging of HCT 116 cells}


Cells were seeded in a 60-mm dish and incubated with $50 \mu \mathrm{g} / \mathrm{mL} \mathrm{SiO}{ }_{2} @ A u @ A u_{4-F B T}$ at $37^{\circ} \mathrm{C}$ for $24 \mathrm{~h}$. After incubation, the culture medium was removed, and the cells were washed thrice with $1 \times$ phosphatebuffer saline (PBS). The cells were fixed with $4 \%$ paraformaldehyde for $1 \mathrm{~h}$, washed with PBS, and dried at room temperature. Then, the SERS mapping images were obtained by point-by-point mapping with a 1$\mu \mathrm{m}$ step size using a $\times 100$ objective lens with a $785-\mathrm{nm}$ excitation source, $0.3-\mathrm{mW}$ laser power, and 1-s acquisition time.

\section{Depth profile evaluation of $\mathrm{SiO}_{2} @ A u @ A u$ SERS signal}

To investigate the depth profile of $\mathrm{SiO}_{2} @ A u @ A u$ SERS signal, NPs were injected into a porcine tissue, and Raman spectra were measured. First, $15 \mu \mathrm{L}$ of $\mathrm{SiO}_{2} @ A u @ A u_{4-\mathrm{FBT}}(1 \mathrm{mg} / \mathrm{mL})$ was dispersed in DW and injected into the porcine tissue with a 26-gauge syringe at different depths $(1,3,5,7$, and $9 \mathrm{~mm})$. SERS signals of NPs inside the tissue were measured immediately after injection under $\times 10$ objective lens. A 785-nm excitation source with 2.1-mW laser power and 10-s acquisition time was used for measurement.

\section{In vivo multiplexing SERS imaging}

To conduct multiplexing SERS imaging in nude mice, 14 types of RLCs (4-MBT, 4-MBA, 4-FBT, 4-MPBA, 4BBT, 4-ATP, 4-CBT, 3,4-DCT, 2-BBT, 3,5-DCT, BT, 2-FBT, 4-MP, and 2-NT) were conjugated to $\mathrm{SiO}_{2} @ A u @ A u$. After adaptation for 1 week, the mice were euthanized and subcutaneously injected with $15 \mu \mathrm{L}$ of

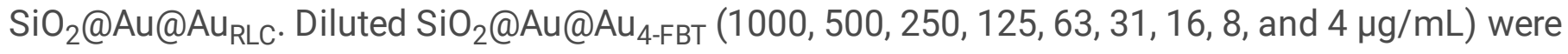
injected into another mouse. Each measurement was performed under $\times 10$ objective lens using a $785 \mathrm{~nm}$ excitation source with 2.1 laser power and $10 \mathrm{~s}$ acquisition time. The mice were maintained in accordance with the guidelines approved by the Konkuk University Animal Care and Use Committee (IACUC).

\section{Results And Discussion}

\section{Characterization and SERS properties of $\mathrm{SiO}_{2} @ A u @ A u$}

$\mathrm{SiO}_{2} @ A u @ A u$ NPs were prepared using a method in our previous work, with modifications [42]. Briefly, $\mathrm{SiO}_{2} @ \mathrm{Au} @ A u$ was prepared by introducing Au NPs into $\mathrm{SiO}_{2}$ to facilitate Au growth (Fig. 1). $\mathrm{SiO}_{2} \mathrm{NPs}$ were prepared as per the Stöber method (Fig. S1). Au NPs were subsequently introduced into $\mathrm{SiO}_{2}$ following treatment with APTS. $\mathrm{SiO}_{2} @$ Au was then used as the seed in the seed-mediated growth method (Fig. S2). SiO $2 @$ Au seed (195.30 $\pm 13.16 \mathrm{~nm}$ ) contained several very small Au NPs (3 nm) attached to the $\mathrm{SiO}_{2} \mathrm{NP}$ surface. It is imperative to control the size of Au NPs on the $\mathrm{SiO}_{2}$ core to achieve gap-enhanced SERS efficacy. This results in a strong local field between the Au NP gaps. In this regard, $\mathrm{SiO}_{2} @ A u @ A u$ NPs were fabricated using $\mathrm{SiO}_{2} @ A u$ NP as the seed with varying concentrations of Au precursor $(50,100$, 200, 300, 400, and $500 \mu \mathrm{M})$. After the growth process, each of the six prepared $\mathrm{SiO}_{2} @ A u @ A u$ NPs were $212.80 \pm 7.35,213.54 \pm 7.14,215.81 \pm 8.30,219.56 \pm 9.36,229.47 \pm 9.85$, and $229.48 \pm 7.27 \mathrm{~nm}$ in size, 
corresponding to Au precursor concentrations of $50,100,200,300,400$, and $500 \mu \mathrm{M}$, respectively (Fig. 2). As more Au precursors were added, the overall size of the NPs increased owing to the growth of $\mathrm{Au}$ NPs. The concentration of added Au precursor was up to $500 \mu \mathrm{M}$ to prevent merged structures (extinction of particle features in Au NP morphology) and seedings excluding Au NPs (Fig. S3). Using the above synthetic process, the seed-mediated growth method allowed dense packing of Au NPs on the $\mathrm{SiO}_{2}$ core surface in contrast to the direct attachment of large-sized Au NPs onto $\mathrm{SiO}_{2}$ cores (Fig. S4).

Fig. 3a shows the absorbance of each prepared $\mathrm{SiO}_{2} @ A u @ A u$ NP. The absorption intensity increased at all wavelengths as the Au precursor concentration increased, especially in the NIR region. In addition, the maximum absorption wavelength $\left(\lambda_{\max }\right)$ showed a red shift with an increase in the concentration of $\mathrm{Au}$ precursor. This phenomenon is attributed to the strong plasmonic coupling from the growth of Au NPs on $\mathrm{SiO}_{2} \mathrm{NP}$ surface. As the absorbance changed, the color of the NPs dispersed in the solvent (ethanol) changed from light pink to dark blue (Fig. 3b).

To investigate the SERS characteristics of $\mathrm{SiO}_{2} @ A u @ A u$, the SERS spectra of six $\mathrm{SiO}_{2} @ A u @ A u$ NPs after treatment with 4-FBT were measured using three laser lines (532, 660, and $785 \mathrm{~nm})$ (Fig. 3c, Fig. S4). Raman signals were not observed for all six $\mathrm{SiO}_{2} @ A u @ \mathrm{Au}_{4-\mathrm{FBT}} \mathrm{NPs}$ at 532 nm under our detection conditions (Fig. S4a). This is owing to the relatively weak plasmonic resonances of all $\mathrm{SiO}_{2} @ A u @ A u$ NPs irradiated with light with a wavelength of $532 \mathrm{~nm}$. The SERS spectra obtained after treatment with light from a 660-nm laser revealed distinguishable bands for $\mathrm{SiO}_{2} @ A u @ A u$ NPs treated with 200, 300, 400, and $500 \mu \mathrm{M}$ of Au precursor (Fig. S4b). SERS signals measured using $785 \mathrm{~nm}$ laser were stronger than those obtained using 532nm laser and 660 nm laser, with the exception of $\mathrm{SiO}_{2} @ A u @ A u$ NPs treated with $50 \mu \mathrm{M}$ of Au precursor for which no signal was detected (Fig. 3c, Fig. S5). Comparison of the 4-FBT SERS signal of $\mathrm{SiO}_{2} @ A u @ A u$ with the most grown Au NPs at $1075 \mathrm{~cm}^{-1}$ peak showed that the Raman intensity was 7.7 times higher than that measured with 660-nm laser (Fig. 3d).

The SERS spectra of $\mathrm{SiO}_{2} @ \mathrm{Au} @ A u$ NPs captured using 660- and 785-nm lasers showed stronger Raman signals, with an increase in the number of $\mathrm{Au} \mathrm{NPs}$ on $\mathrm{SiO}_{2}$ surfaces. This could be attributed not only to the stronger absorption features but also to the narrower nanogap between Au NPs, leading to a highly amplified SERS signal. Transmission electron microscopy (TEM) images in Fig. 2 show that the nanogaps between the Au NPs on the $\mathrm{SiO}_{2}$ cores gradually decreased as the Au NP concentration increased. The sizes of nanogaps were measured and found to be $4.16 \pm 1.04,3.76 \pm 1.09,3.68 \pm 1.29$, $1.98 \pm 0.50,1.17 \pm 0.32$, and $0.98 \pm 0.19 \mathrm{~nm}$ for NPs treated with $50,100,200,300,400$, and $500 \mu \mathrm{M} \mathrm{Au}$ precursor, respectively (Fig. 3e). The strongest Raman signal of $\mathrm{SiO}_{2} @ A u @ A u$ NPs with $500 \mu \mathrm{M}$ of $\mathrm{Au}$ precursor during Au seed growth is thought to be produced from a locally concentrated electromagnetic field with 1-nm gaps. Our seeded growth method for $\mathrm{SiO}_{2} @ A u @ A u$ NPs was validated as a powerful strategy to finely control the nanogap size and maximize SERS enhancement.

Based on the above measurements, our experiment proceeded with $\mathrm{SiO}_{2} @ A u @ A u$ NPs prepared using $500 \mu \mathrm{M}$ of the Au precursor. Using 4-FBT molecule as an RLC, the SERS spectra from 20 particles of 
single $\mathrm{SiO}_{2} @ A u @ \mathrm{Au}_{4-\mathrm{FBT}}$ were measured, and the average EF value was calculated to be $3.8 \times 10^{6}$ with good uniformity (3.45\% relative standard deviation of log scale) (Fig. 3f). In comparison to other noble metal-based NPs, the assembled structure had a lower EF value owing to the large surface area for RLC binding. However, the higher intensity and signal uniformity of each single nanocomposite could be advantageous features of assembled structures [44]. $\mathrm{SiO}_{2} @ A u @ A u$ has higher EF values

than those reported for other noble metal-assembled NPs (Table 1). Although the EF value is smaller than that of bumpy silver nanoshells, Au-assembled $\mathrm{SiO}_{2} \mathrm{NPs}$ are more stable than Ag-based NPs under biological conditions [45].

\section{HCT 116 cancer cell SERS imaging with $\mathrm{SiO}_{2} @ A u @ A u_{4-F B T}$}

Before applying $\mathrm{SiO}_{2} @ \mathrm{Au} @ A u$ for in vitro applications, a cytotoxicity test was conducted using HCT 116 cell line.SiO ${ }_{2} @ A u @ A u_{4-F B T} N P s$ were prepared at $62.5 \mu \mathrm{g} / \mathrm{mL}$ concentration $\left(26.38 \times 10^{8}\right.$ particles $\left./ \mathrm{mL}\right)$ and serially diluted for the cytotoxicity test (Fig. S6). Within $24 \mathrm{~h}$, the cell viability was over $90 \%$ at all concentrations of $\mathrm{SiO}_{2} @ A u @ A u$ NPs. The biocompatibility of the $\mathrm{SiO}_{2} @ A u @ A u_{4-\mathrm{FBT}} \mathrm{NPs}$ at $62.5 \mathrm{\mu g} / \mathrm{mL}$ or lower concentrations was confirmed.

To image HCT 116 cancer cells through SERS, the cells were incubated with $\mathrm{SiO}_{2} @ A u @ A u_{4-F B T}$ NPs for $24 \mathrm{~h}$. The NPs were found to be attached to the cell surface or had entered the cells. NPs that did not bind to or enter the cells were washed out. Fig. S7a shows the SERS mapping image at $1075 \mathrm{~cm}^{-1}$. The overlaid image of HCT 116 cells with the adsorbed NPs showed that the $\mathrm{SiO}_{2} @ A u @ A u_{4-F B T}$ NPs were stuck on the edge of the cell. We compared the Raman intensities for different locations on cells, and found no Raman signal outside the cell (i), weak Raman signal at the cell surface (ii), and a very strong Raman signal inside the cell (iii) (Fig. S7b). This observation confirms that SERS imaging of cancer cells is possible using $\mathrm{SiO}_{2} @ A u @ A u$ NPs.

\section{Sensitivity of SERS signal of $\mathrm{SiO}_{2} @ \mathrm{Au} @ A \mathrm{u}_{4-\mathrm{FBT}}$}

To investigate the SERS signal depth profile of $\mathrm{SiO}_{2} @ A u @ A u$, we injected the $\mathrm{SiO}_{2} @ A u @ A u_{4-\mathrm{FBT}} \mathrm{NPs}$ into porcine tissues at different depths $(1,3,5,7$, and $9 \mathrm{~mm}$ ), and measured the SERS spectra (Fig. 4a). As the depth increased, the Raman intensity decreased (Fig. 4b). However, a readable signal up to a depth of 7 $\mathrm{mm}$ was measured. For accurate analysis, the Raman band intensities at 382,620 , and $1075 \mathrm{~cm}^{-1}$ were normalized to the signal intensity at a depth of $1 \mathrm{~mm}$ (Fig. 4c). We conclude that $\mathrm{SiO}_{2} @ A u @ A u$ NPs generated a SERS signal that was sufficient for detection in animal tissues, and that the maximum depth was 7 mm. Thus, SERS detection using $\mathrm{SiO}_{2} @ A u @ A u$ NPs was attempted through their subcutaneous injection into animals.

For in vivo imaging, it is very important to use small amounts of NPs to avoid side-effects, such as blood

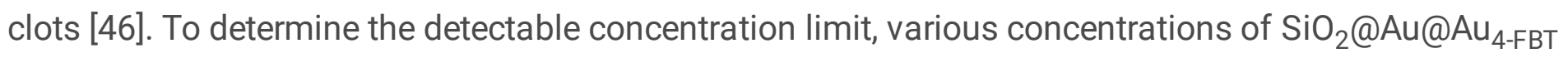
from 1000 to $4 \mu \mathrm{g} / \mathrm{mL}$ were subcutaneously injected into nude mice, and the SERS spectra were 
measured using $785 \mathrm{~nm}$ laser (Fig. 5a and 5b). The Raman intensities decreased as the concentration of $\mathrm{SiO}_{2} @ \mathrm{Au} @ \mathrm{Au}_{4-\mathrm{FBT}} \mathrm{NPs}$ decreased; however, a sufficient signal was observed at a concentration of 16 $\mu \mathrm{g} / \mathrm{mL}$ (Fig. 5c). To compare these results, the Raman bands at 382,620 , and $1075 \mathrm{~cm}^{-1}$ were normalized to the Raman signal at $1000 \mu \mathrm{g} / \mathrm{mL}$ (Fig. 5d). The strong SERS signal of our $\mathrm{SiO}_{2} @ A u @ \mathrm{Au}_{4}$ FBT allowed for the subcutaneous detection of particles even at a very low concentration $(16 \mu \mathrm{g} / \mathrm{mL})$, showing sufficient signal sensitivity.

\section{Possibility of in vivo multiplexed imaging}

To investigate the multiplexed imaging potential of $\mathrm{SiO}_{2} @ \mathrm{Au} @ \mathrm{Au}, 14$ different RLC-treated NPs $\left(\mathrm{SiO}_{2} @ A u @ A u_{\mathrm{RLC}}\right)$ were prepared and subcutaneously injected into nude mice (Fig. 6a). The Raman spectra from each location were measured using $785 \mathrm{~nm}$ laser. Distinct Raman spectra were obtained for all 14 types of NPs (Fig. 6b), which showed unique bands for code (label) identification (4-MBT, $324 \mathrm{~cm}^{-1}$; 4-MBA, $332 \mathrm{~cm}^{-1}$; 4-FBT, $347 \mathrm{~cm}^{-1}$; 4-MPBA, $469 \mathrm{~cm}^{-1}$; 4-BBT, $494 \mathrm{~cm}^{-1}$; 4-ATP, $503 \mathrm{~cm}^{-1}$; 4-CBT, 536 $\mathrm{cm}^{-1}$; 3,4-DCT, $563 \mathrm{~cm}^{-1}$; 2-BBT, $710 \mathrm{~cm}^{-1}$; 3,5-DCT, $782 \mathrm{~cm}^{-1}$; BT, $1020 \mathrm{~cm}^{-1}$; 2-FBT, $1115 \mathrm{~cm}^{-1}$; 4-MP, $1168 \mathrm{~cm}^{-1}$; and 2-NT, $1378 \mathrm{~cm}^{-1}$ ). To the best of our knowledge, this is the highest number of labels for NIR active nanoprobes, as the previously reported maximum number of RLCs for multiplexing imaging based on SERS was 10 [47]. Thus, our $\mathrm{SiO}_{2} @ A u @ A u$ NPs with a hotspot-abundant structure and a very narrow nanogap showed high stability, allowing attachment of 14 different RLCs.

\section{Conclusion}

In summary, $\mathrm{SiO}_{2} @ A u @ A u$ NPs were prepared using a seed-mediated growth method. In the synthesis process, six $\mathrm{SiO}_{2} @ A u @ A u$ NPs with different sizes were fabricated on the surface of $\mathrm{SiO}_{2} \mathrm{NPs}$ by controlling the concentration of the Au precursor $(50,100,200,300,400$, and $500 \mu \mathrm{M})$. These $\mathrm{SiO}_{2} @ A u @ A u$ showed stronger absorbance, especially in the NIR region, as more Au precursors were added. In addition, hotspot-abundant structures with narrow nanogaps $(\sim 1 \mathrm{~nm})$ were obtained by increasing the concentration of the Au precursor during the growth process, enabling the detection of a single NP. The SERS measurement revealed a very strong signal after excitement using a 785-nm laser. $\mathrm{SiO}_{2} @ A u @ A u$ NPs obtained with $500 \mu \mathrm{M}$ of Au precursor exhibited an average SERS EF value of $3.83 \times$ $10^{6}$. The $\mathrm{SiO}_{2} @ A u @ A u$ NPs were successfully applied for the SERS imaging of HCT 116 cancer cells. In addition, based on the advantage of NIR radiation and detection, the SERS signal appeared even at a depth of $7 \mathrm{~mm}$ in porcine tissues. The concentration limit of subcutaneous detection was $16 \mu \mathrm{g} / \mathrm{mL}$. The multiplexing capability of our $\mathrm{SiO}_{2} @ A u @ A u$ was also investigated by subcutaneously injecting 14 different types of $\mathrm{SiO}_{2} @ A u @ A u_{\mathrm{RLC}}$ into nude mice. In this study, we fabricated highly sensitive NIR SERS nanoprobes with very strong SERS signals obtained due to the uniformly synthesized hotspot structure and narrow nanogaps. With the advantageous features of absorbing long-wavelength light and highly enhanced Raman signals, our $\mathrm{SiO}_{2} @ A u @ A u$ structure can potentially be applied for multiplex molecular imaging and in vivo applications. 


\section{Abbreviations}

AA: ascorbic acid; APTS: (3-aminopropyl)triethoxysilane; ATCC: American Type Culture Collection; BT: benzenethiol; DW: Deionized water; EtOH: Ethanol; FBS: Fetal bovine serum; $\mathrm{HAuCl}_{4}$ : gold (III) chloride trihydrate; $\mathrm{NaOH}$ : Sodium hydroxide; $\mathrm{NH}_{4} \mathrm{OH}$ : aqueous ammonium hydroxide; NIR: Near-infrared; NPs: Nanoparticles; PBS: Phosphate-buffered saline; PTT: photothermal therapy; PVP: polyvinylpyrrolidone; RLCs: Raman labeling compounds; SERS: Surface-enhanced Raman spectroscopy; SDS: Sodium dodecyl sulphate; $\mathrm{SiO}_{2}$ : Silica; $\mathrm{SiO}_{2} @ A u @ A u:$ Au-assembled silica nanoparticle; TEOS: Tetraethyl orthosilicate; THPC: tetrakis(hydroxymethyl)phosphonium chloride; 2-BBT: 2-bromobenzenethiol; 2-FBT: 2fluorobenzenethiol; 2-NT: 2-naphthalenethiol; 3,4-DCT: 3,4-dichlorobenzenethiol; 3,5-DCT: 3,5dichlorobenzenethiol; 4-ATP: 4-aminothiophenol; 4-BBT: 4-bromobenzenethiol; 4-CBT: 4chlorobenzenethiol; 4-FBT: 4-fluorobenzenethiol; 4-MBA: 4-mercaptobenzoic acid; 4-MBT: 4methylbenzenethiol; 4-MP: 4-mercaptophenol; 4-MPBA: 4-mercaptophenyl boronic acid;

\section{Declarations}

\section{Ethics approval and consent to participate}

Not applicable.

\section{Consent for publication}

Not applicable.

\section{Availability of data and materials}

All data generated or analyzed during this study are included in this manuscript and its supplementary material.

\section{Competing interests}

The authors declare that they have no competing interests.

\section{Funding}

This research was funded by the National Research Foundation (NRF) of Korea and by the Korean Government (MSIT) (NRF-2017H1A2A1044051)

\section{Author's contribution}

S.B., X.-H.P., and B.-H.J. conceived the idea and designed the experiments. S.B., Y.-S.C., M.K., Y.Y., J.K., B.S., W.K., A.J., K.-M.H., and S.G.L. performed the experiments. S.H.L., H.K., H.S.C., and D.H.J. analyzed the data. S.B. wrote the manuscript. H.C., D.-E.K., and B.-H.J. supervised the research. All authors have approved the final version of the manuscript. 
$\ddagger$ These authors contributed equally.

\section{Acknowledgement}

Not applicable

\section{Author's information}

${ }^{1}$ Department of Bioscience and Biotechnology, Konkuk University, Seoul 05029, South Korea;

${ }^{2}$ Department of Chemistry Education, Seoul National University, Seoul 08826, South Korea;

${ }^{3}$ Department of Chemical and Biological Engineering, Hanbat National University, Deajeon 34158, South Korea;

${ }^{4}$ Gordon Center for Medical Imaging, Department of Radiology, Massachusetts General Hospital and Harvard Medical School, Boston, MA 02114, USA

${ }^{5}$ Division of Science Education, Kangwon National University, Chuncheon 24341, south Korea

\section{References}

1. Weissleder R: A clearer vision for in vivo imaging. Nat Biotechnol 2001, 19:316-317.

2. Yuan L, Lin W, Zhao S, Gao W, Chen B, He L, Zhu S: A unique approach to development of nearinfrared fluorescent sensors for in vivo imaging. Journal of the American Chemical Society 2012, 134:13510-13523.

3. Kim JS, Kim Y-H, Kim JH, Kang KW, Tae EL, Youn H, Kim D, Kim S-K, Kwon J-T, Cho M-H: Development and in vivo imaging of a PET/MRI nanoprobe with enhanced NIR fluorescence by dye encapsulation. Nanomedicine 2012, 7:219-229.

4. Fan Y, Wang P, Lu Y, Wang R, Zhou L, Zheng X, Li X, Piper JA, Zhang F: Lifetimeengineered NIR-II nanoparticles unlock multiplexed in vivo imaging. Nature nanotechnology 2018, 13:941-946.

5. Koide Y, Urano Y, Hanaoka K, Piao W, Kusakabe M, Saito N, Terai T, Okabe T, Nagano T: Development of NIR fluorescent dyes based on Si-rhodamine for in vivo imaging. Journal of the American Chemical Society 2012, 134:5029-5031.

6. Zhou J, Sun Y, Du X, Xiong L, Hu H, Li F: Dual-modality in vivo imaging using rareearth nanocrystals with near-infrared to near-infrared (NIR-to-NIR) upconversion luminescence and magnetic resonance properties. Biomaterials 2010, 31:3287-3295.

7. Haraguchi T, Shimi T, Koujin T, Hashiguchi N, Hiraoka Y: Spectral imaging fluorescence microscopy. Genes to Cells 2002, 7:881-887.

8. Keren S, Zavaleta C, Cheng Zd, de La Zerda A, Gheysens O, Gambhir S: Noninvasive molecular imaging of small living subjects using Raman spectroscopy. Proceedings of the National Academy 
of Sciences 2008, 105:5844-5849.

9. Chang H, Kang H, Yang J-K, Jo A, Lee H-Y, Lee Y-S, Jeong DH: Ag Shell-Au Satellite HeteroNanostructure for Ultra-Sensitive, Reproducible, and Homogeneous NIR SERS Activity. ACS applied materials \& interfaces 2014, 6:11859-11863.

10. Nolan JP, Duggan E, Liu E, Condello D, Dave I, Stoner SA: Single cell analysis using surface enhanced Raman scattering (SERS) tags. Methods 2012, 57:272-279.

11. Schlücker S: Surface-Enhanced raman spectroscopy: Concepts and chemical applications. Angewandte Chemie International Edition 2014, 53:4756-4795.

12. Sharma B, Frontiera RR, Henry A-I, Ringe E, Van Duyne RP: SERS: Materials, applications, and the future. Materials today 2012, 15:16-25.

13. Lim D-K, Jeon K-S, Kim HM, Nam J-M, Suh YD: Nanogap-engineerable Raman-active nanodumbbells for single-molecule detection. Nature materials 2010, 9:60-67.

14. Kneipp J, Kneipp H, Kneipp K: SERS-a single-molecule and nanoscale tool for bioanalytics. Chemical Society Reviews 2008, 37:1052-1060.

15. Hahm E, Kim Y-H, Pham X-H, Jun B-H: Highly reproducible surfaceenhanced Raman scattering detection of alternariol using silver-embedded silica nanoparticles. Sensors 2020, 20:3523.

16. Pham X-H, Hahm E, Huynh K-H, Kim H-M, Son BS, Jeong DH, Jun B-H: Sensitive and selective detection of 4-aminophenol in the presence of acetaminophen using gold-silver core-shell nanoparticles embedded in silica nanostructures. Journal of Industrial and Engineering Chemistry 2020, 83:208-213.

17. Kang H, Koh Y, Jeong S, Jeong C, Cha MG, Oh M-H, Yang J-K, Lee H, Jeong DH, Jun B-H: Graphical and SERS dual-modal identifier for encoding OBOC library. Sensors and Actuators B: Chemical 2020, 303:127211.

18. Pham X-H, Hahm E, Kang E, Son BS, Ha Y, Kim H-M, Jeong DH, Jun B-H: Control of silver coating on Raman label incorporated gold nanoparticles assembled silica nanoparticles. International journal of molecular sciences 2019, 20:1258.

19. Pham X-H, Hahm E, Kim TH, Kim H-M, Lee SH, Lee SC, Kang H, Lee H-Y, Jeong DH, Choi HS: Enzymeamplified SERS immunoassay with Ag-Au bimetallic SERS hot spots. Nano Research 2020, 13:33383346.

20. Jin Y: Engineering plasmonic gold nanostructures and metamaterials for biosensing and nanomedicine. Advanced Materials 2012, 24:5153-5165.

21. Han J, Zhang J, Yang M, Cui D, Jesus M: Glucose-functionalized Au nanoprisms for optoacoustic imaging and near-infrared photothermal therapy. Nanoscale 2015, 8:492-499.

22. Du L, Suo S, Wang G, Jia H, Liu KJ, Zhao B, Liu Y: Mechanism and Cellular Kinetic Studies of the Enhancement of Antioxidant Activity by Using Surface-Functionalized Gold Nanoparticles. Chemistry-A European Journal 2013, 19:1281-1287. 
23. Zeng S, Yong K-T, Roy I, Dinh X-Q, Yu X, Luan F: A review on functionalized gold nanoparticles for biosensing applications. Plasmonics 2011, 6:491-506.

24. Frederix F, Friedt J-M, Choi K-H, Laureyn W, Campitelli A, Mondelaers D, Maes G, Borghs G: Biosensing based on light absorption of nanoscaled gold and silver particles. Anal Chem 2003, 75:6894-6900.

25. Zhao W, Brook MA, Li Y: Design of gold nanoparticle-based colorimetric biosensing assays. ChemBioChem 2008, 9:2363-2371.

26. Murphy CJ, Gole AM, Stone JW, Sisco PN, Alkilany AM, Goldsmith EC, Baxter SC: Gold nanoparticles in biology: beyond toxicity to cellular imaging. Accounts of chemical research 2008, 41:1721-1730.

27. Huang X, Jain PK, El-Sayed IH, El-Sayed MA: Plasmonic photothermal therapy (PPTT) using gold nanoparticles. Lasers in medical science 2008, 23:217-228.

28. Anker JN, Hall WP, Lyandres O, Shah NC, Zhao J, Van Duyne RP: Biosensing with plasmonic nanosensors. Nanoscience and Technology: A Collection of Reviews from Nature Journals 2010:308319.

29. Daniel M-C, Astruc D: Gold nanoparticles: assembly, supramolecular chemistry, quantum-size-related properties, and applications toward biology, catalysis, and nanotechnology. Chemical reviews 2004, 104:293-346.

30. Kelly KL, Coronado E, Zhao LL, Schatz GC: The optical properties of metal nanoparticles: the influence of size, shape, and dielectric environment. J Phys Chem B 2003, 107:668-677.

31. Sun Y, Xia Y: Shape-controlled synthesis of gold and silver nanoparticles. science 2002, 298:21762179.

32. Lewinski N, Colvin V, Drezek R: Cytotoxicity of nanoparticles. small 2008, 4:26-49.

33. Connor EE, Mwamuka J, Gole A, Murphy CJ, Wyatt MD: Gold nanoparticles are taken up by human cells but do not cause acute cytotoxicity. Small 2005, 1:325-327.

34. Giljohann DA, Seferos DS, Daniel WL, Massich MD, Patel PC, Mirkin CA: Gold nanoparticles for biology and medicine. Angewandte Chemie International Edition 2010, 49:3280-3294.

35. Lai C-H, Wang G-A, Ling T-K, Wang T-J, Chiu P-k, Chau Y-FC, Huang C-C, Chiang H-P: Near infrared surfaceenhanced Raman scattering based on star-shaped gold/silver nanoparticles and hyperbolic metamaterial. Scientific reports 2017, 7:1-8.

36. Huang J, Zhang L, Chen B, Ji N, Chen F, Zhang Y, Zhang Z: Nanocomposites of size-controlled gold nanoparticles and graphene oxide: formation and applications in SERS and catalysis. Nanoscale 2010, 2:2733-2738.

37. Ando J, Fujita K, Smith NI, Kawata S: Dynamic SERS imaging of cellular transport pathways with endocytosed gold nanoparticles. Nano letters 2011, 11:5344-5348.

38. Polavarapu L, Xu Q-H: Water-soluble conjugated polymer-induced self-assembly of gold nanoparticles and its application to SERS. Langmuir 2008, 24:10608-10611.

39. Song C, Li F, Guo X, Chen W, Dong C, Zhang J, Zhang J, Wang L: Gold nanostars for cancer celltargeted SERS-imaging and NIR light-triggered plasmonic photothermal therapy (PPTT) in the first 
and second biological windows. Journal of Materials Chemistry B 2019, 7:2001-2008.

40. You H, Ji Y, Wang L, Yang S, Yang Z, Fang J, Song X, Ding B: Interface synthesis of gold mesocrystals with highly roughened surfaces for surfaceenhanced Raman spectroscopy. Journal of Materials Chemistry 2012, 22:1998-2006.

41. Pazos-Perez N, Fitzgerald JM, Giannini V, Guerrini L, Alvarez-Puebla RA: Modular assembly of plasmonic core-satellite structures as highly brilliant SERS-encoded nanoparticles. Nanoscale Advances 2019, 1:122-131.

42. Seong B, Bock S, Hahm E, Huynh K-H, Kim J, Lee SH, Pham X-H, Jun B-H: Synthesis of Densely Immobilized Gold-Assembled Silica Nanostructures. International Journal of Molecular Sciences 2021, 22:2543.

43. Jiang P, Deng K, Fichou D, Xie S-S, Nion A, Wang C: STM imaging ortho-and para-fluorothiophenol self-assembled monolayers on Au (111). Langmuir 2009, 25:5012-5017.

44. Jeon MJ, Ma X, Lee JU, Roh H, Bagot CC, Park W, Sim SJ: Precisely Controlled Three-Dimensional Gold Nanoparticle Assembly Based on Spherical Bacteriophage Scaffold for Molecular Sensing via Surface-Enhanced Raman Scattering. The Journal of Physical Chemistry C 2021, 125:2502-2510.

45. Chang H, Ko E, Kang H, Cha MG, Lee Y-S, Jeong DH: Synthesis of optically tunable bumpy silver nanoshells by changing the silica core size and their SERS activities. RSC advances 2017, 7:4025540261.

46. Ajdari N, Vyas C, Bogan SL, Lwaleed BA, Cousins BG: Gold nanoparticle interactions in human blood: a model evaluation. Nanomedicine: Nanotechnology, Biology and Medicine 2017, 13:1531-1542.

47. Zavaleta CL, Smith BR, Walton I, Doering W, Davis G, Shojaei B, Natan MJ, Gambhir SS: Multiplexed imaging of surface enhanced Raman scattering nanotags in living mice using noninvasive Raman spectroscopy. Proceedings of the National Academy of Sciences 2009, 106:13511-13516.

48. Kim H-M, Jeong S, Hahm E, Kim J, Cha MG, Kim K-M, Kang H, Kyeong S, Pham X-H, Lee Y-S: Large scale synthesis of surfaceenhanced Raman scattering nanoprobes with high reproducibility and long-term stability. Journal of Industrial and Engineering Chemistry 2016, 33:22-27.

49. Kang H, Jeong S, Park Y, Yim J, Jun B-H, Kyeong S, Yang J-K, Kim G, Hong S, Lee LP, et al: NearInfrared SERS Nanoprobes with Plasmonic Au/Ag Hollow-Shell Assemblies for In Vivo Multiplex Detection. Adv Funct Mater 2013, 23:3719-3727.

\section{Tables}

Table 1. Comparison of EF with different metal-assembled NPs 


\begin{tabular}{|c|c|c|c|}
\hline Composition & Nanoparticles (NPs) & $\begin{array}{l}\text { Enhancement factor } \\
\text { (EF) }\end{array}$ & Reference \\
\hline \multirow[t]{2}{*}{ Silver (Ag) } & Silica encapsulated $\mathrm{Ag}-\mathrm{SiO}_{2} \mathrm{NP}$ & $1 \times 10^{5}$ & [48] \\
\hline & Bumpy silver nanoshells & $2.2 \times 10^{7}$ & [45] \\
\hline \multirow[t]{2}{*}{ Gold (Au) } & $\begin{array}{l}\text { Au/Ag hollow shell-assembled silica } \\
\text { nanosphere }\end{array}$ & $2.8 \times 10^{5}$ & [49] \\
\hline & Au-assembled silica nanoparticle & $3.8 \times 10^{6}$ & $\begin{array}{l}\text { This } \\
\text { study }\end{array}$ \\
\hline
\end{tabular}

\section{Figures}
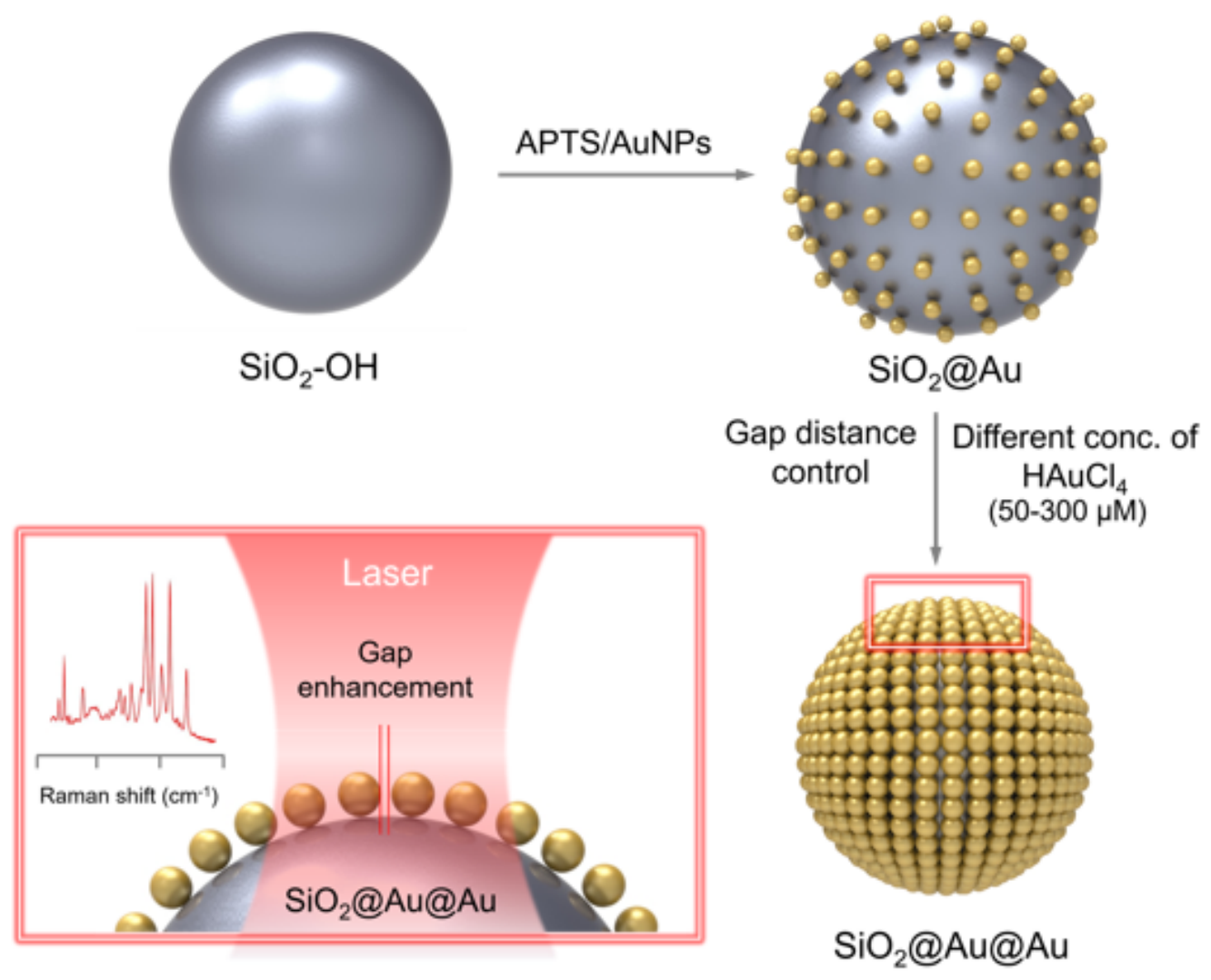

Figure 1

Schematic illustration of the preparation process of $\mathrm{SiO}_{2} @ \mathrm{Au} @ \mathrm{Au}$ with $\mathrm{SiO}_{2} @ \mathrm{Au}$ as a seed. 
(a)

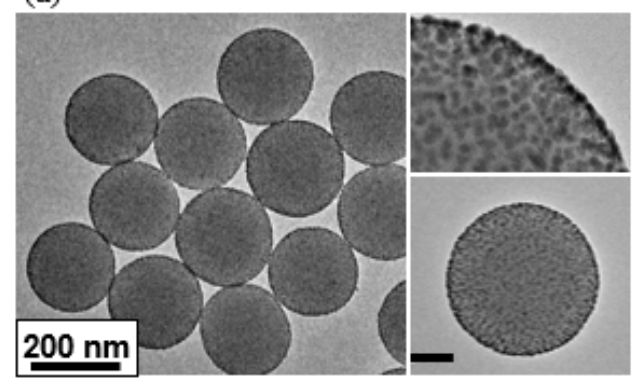

(b)

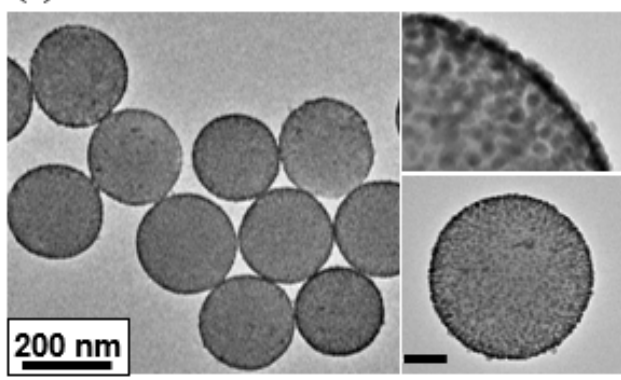

(c)

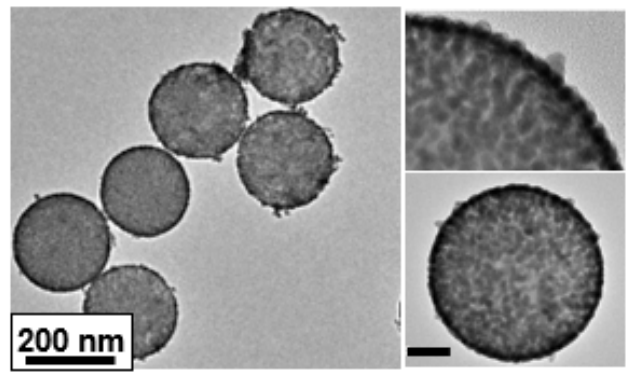

(d)

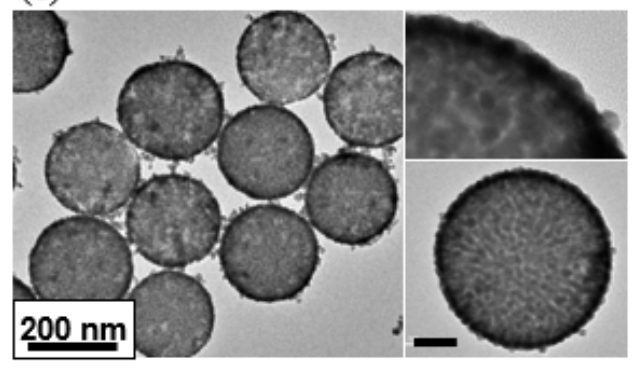

(e)

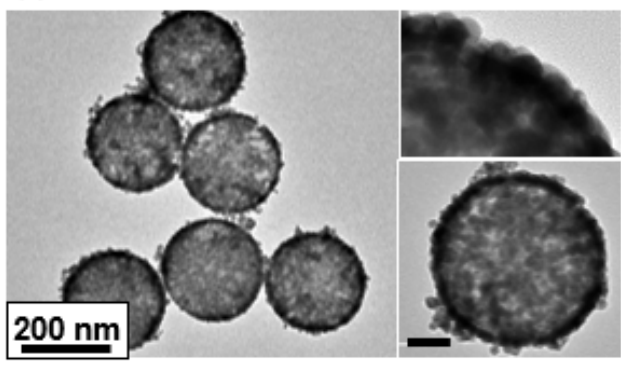

(f)

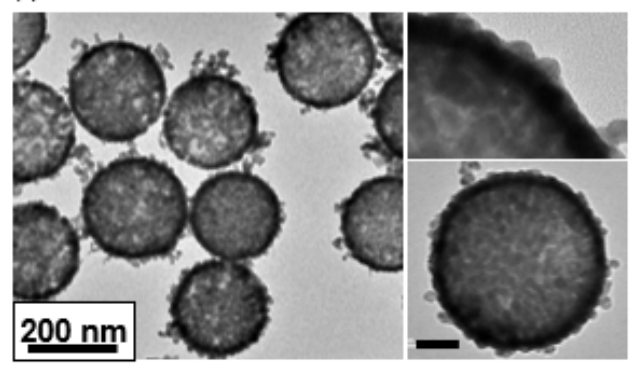

Figure 2

Transmission electron microscopy images of the $\mathrm{SiO}_{2} @ A u @ A u$ synthesized with (a) $50 \mu \mathrm{M}$, (b) $100 \mu \mathrm{M}$, (c) $200 \mu \mathrm{M}$, (d) $300 \mu \mathrm{M}$, (e) $400 \mu \mathrm{M}$, (f) $500 \mu \mathrm{M}$ gold (III) chloride hydrate. Each scale bar of inset images is $50 \mathrm{~nm}$.

(a)

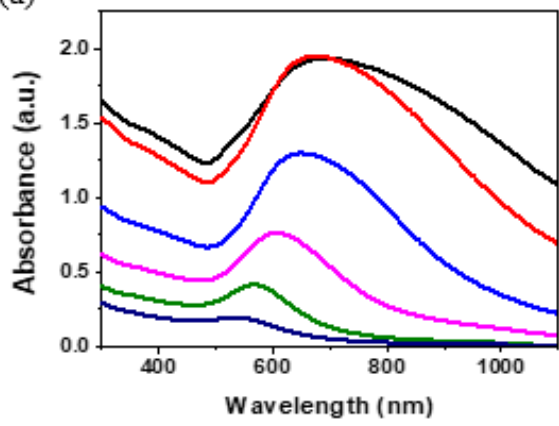

(d)

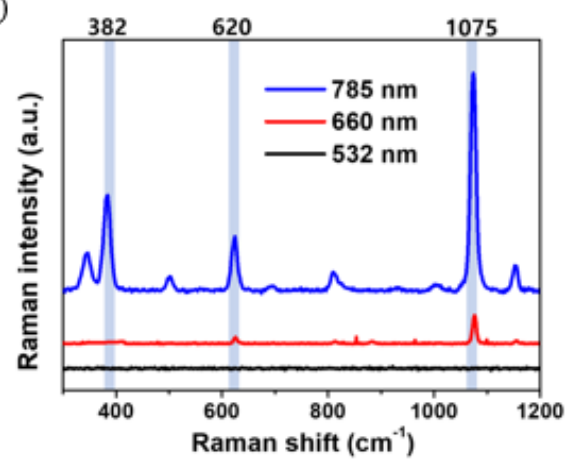

(b)

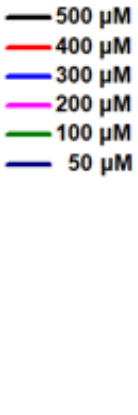

(e)

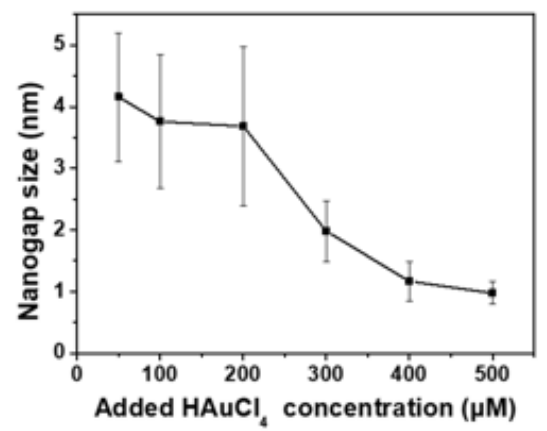

(c)

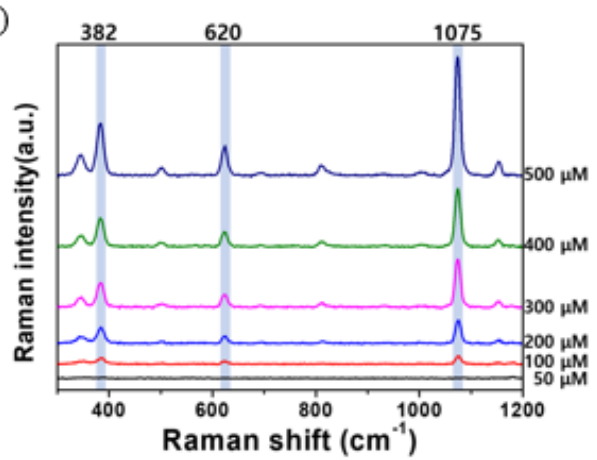

(f)

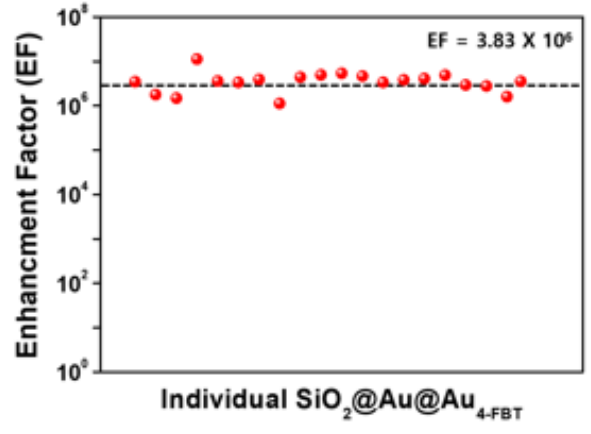




\section{Figure 3}

Characterization of $\mathrm{SiO}_{2} @ A u @ A u$. (a) UV/Vis absorbance spectra of $\mathrm{SiO}_{2} @ A u @ A u$ with various concentrations of gold (III) chloride hydrate and (b) different optical colors of each $\mathrm{SiO}_{2} @ A u @ A u$. (c) Raman intensities of $\mathrm{SiO}_{2} @ A u @ A u$ with various concentrations of gold (III) chloride hydrate captured using a 785 nm laser. (d) Raman intensities of $\mathrm{SiO}_{2} @ A u @ \mathrm{Au}_{4-\mathrm{FBT}}$ with $500 \mu \mathrm{M}$ of gold (III) chloride hydrate using blue visible light $(532 \mathrm{~nm})$, red visible light $(660 \mathrm{~nm})$, and near-infrared (NIR) light (785 nm) as photoexcitation sources. (e) Nanogap size of $\mathrm{SiO}_{2} @ A u @ A u$. (f) Calculated enhancement factor (EF) of single SiO $2 @ A u @ A u_{4-F B T}$ on NIR light based on the SERS intensity of $1075 \mathrm{~cm}^{-1}$.

(a)

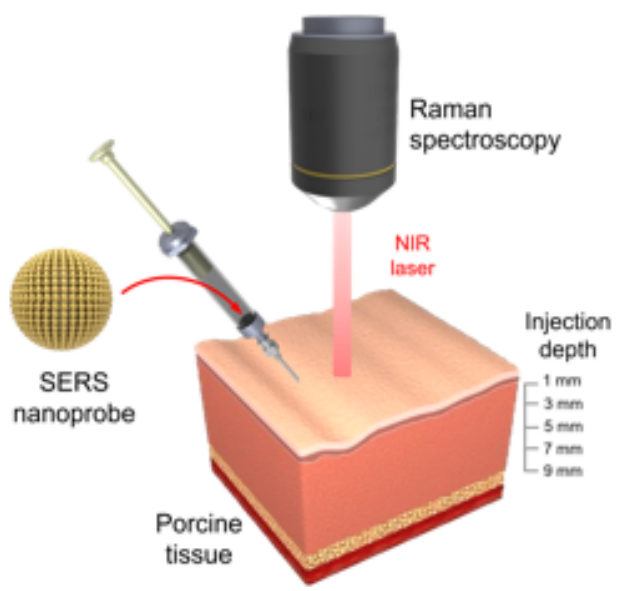

(b)

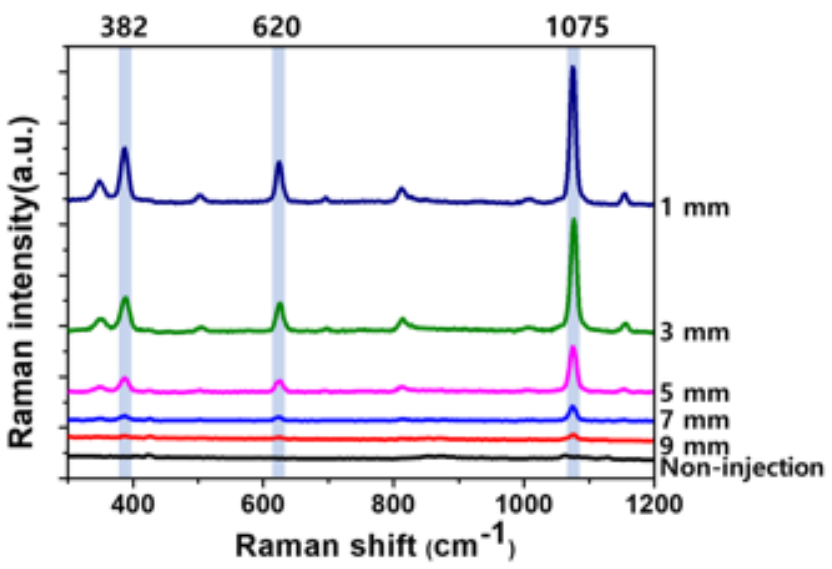

(c)

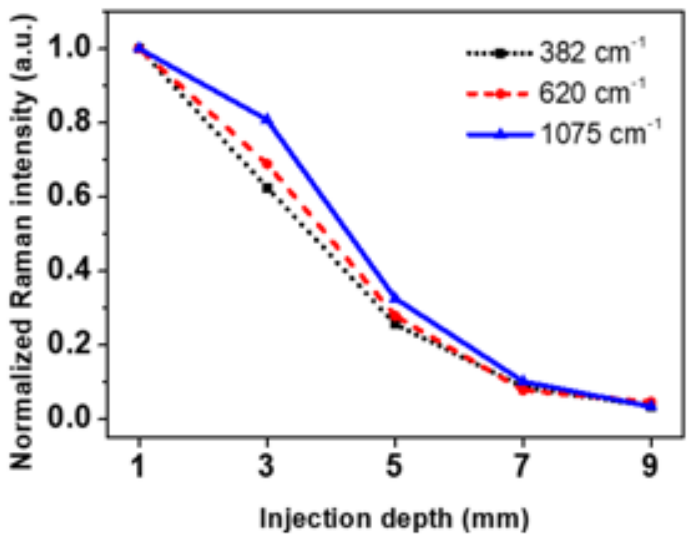

\section{Figure 4}

(a) Schematic illustration for the depth-dependent penetration capability test for $\mathrm{SiO}_{2} @ A u @ A u$ using porcine tissue. (b) Raman spectra of $\mathrm{SiO}_{2} @ A u @ A u$ injected into porcine tissues with different depths (1, $3,5,7$, and $9 \mathrm{~mm}$ ). (c) Correlation between normalized SERS intensities at 382,620 , and $1075 \mathrm{~cm}^{-1}$ for Raman spectra in (b) and the injection depth from the surface of the porcine tissue. The Raman intensity decreased as the depth of $\mathrm{SiO}_{2} @ A u @ A u$ injection increased. 
(a)

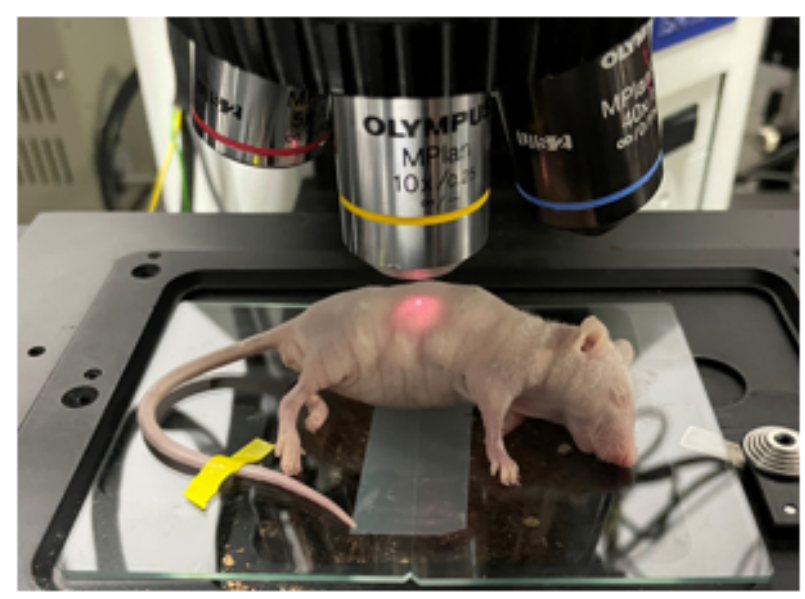

(c)

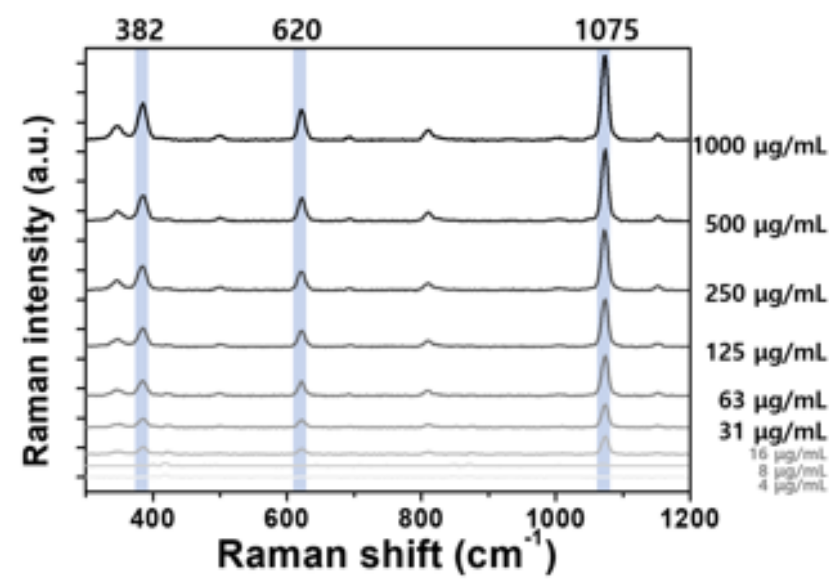

(b)

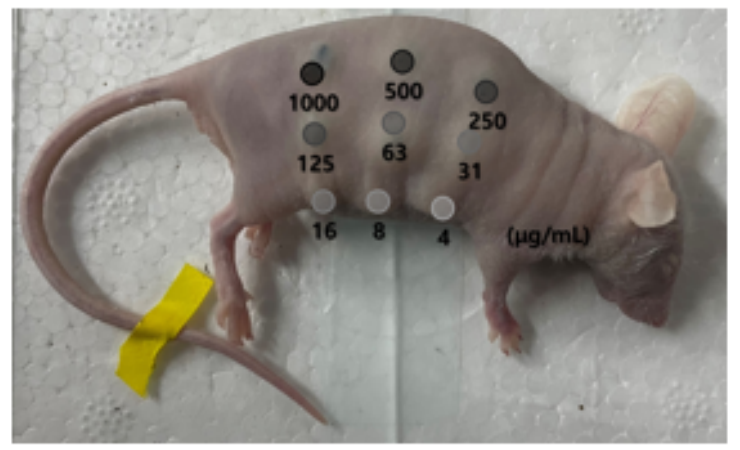

(d)

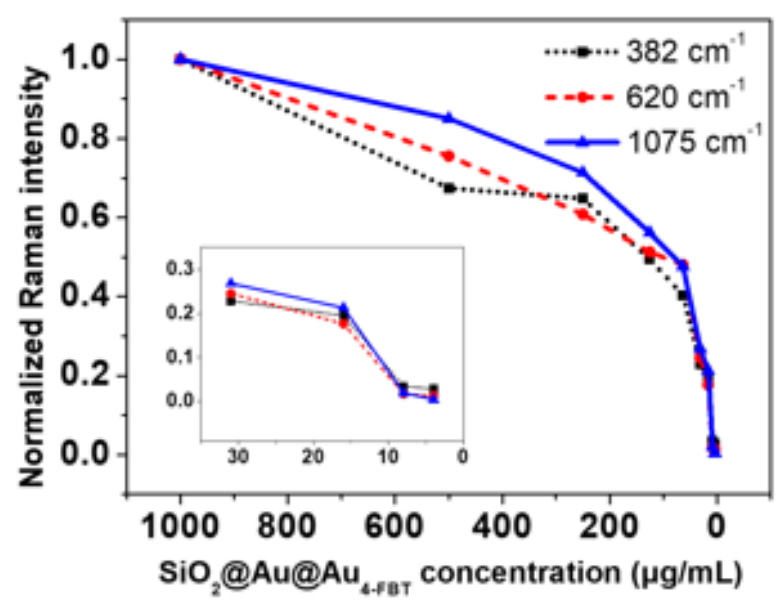

\section{Figure 5}

(a) Photograph of a mouse injected with various concentrations of $\mathrm{SiO}_{2} @ A u @ A u_{4-F B T}$ and $(\mathrm{b})$ the injected position. (c) Raman spectra of $\mathrm{SiO}_{2} @ A u @ \mathrm{Au}_{4-\mathrm{FBT}}$ injected at concentrations from 1000 to $4 \mu \mathrm{g} / \mathrm{mL}$. (d) Normalized Raman intensities at 382, 620, and $1075 \mathrm{~cm}^{-1}$ from Raman spectra in (c). Curves of Raman intensity exhibit logarithmic relation between the $\mathrm{SiO}_{2} @ \mathrm{Au} @ \mathrm{Au}_{4-\mathrm{FBT}}$ concentration and SERS intensity. 
(b)

(a)

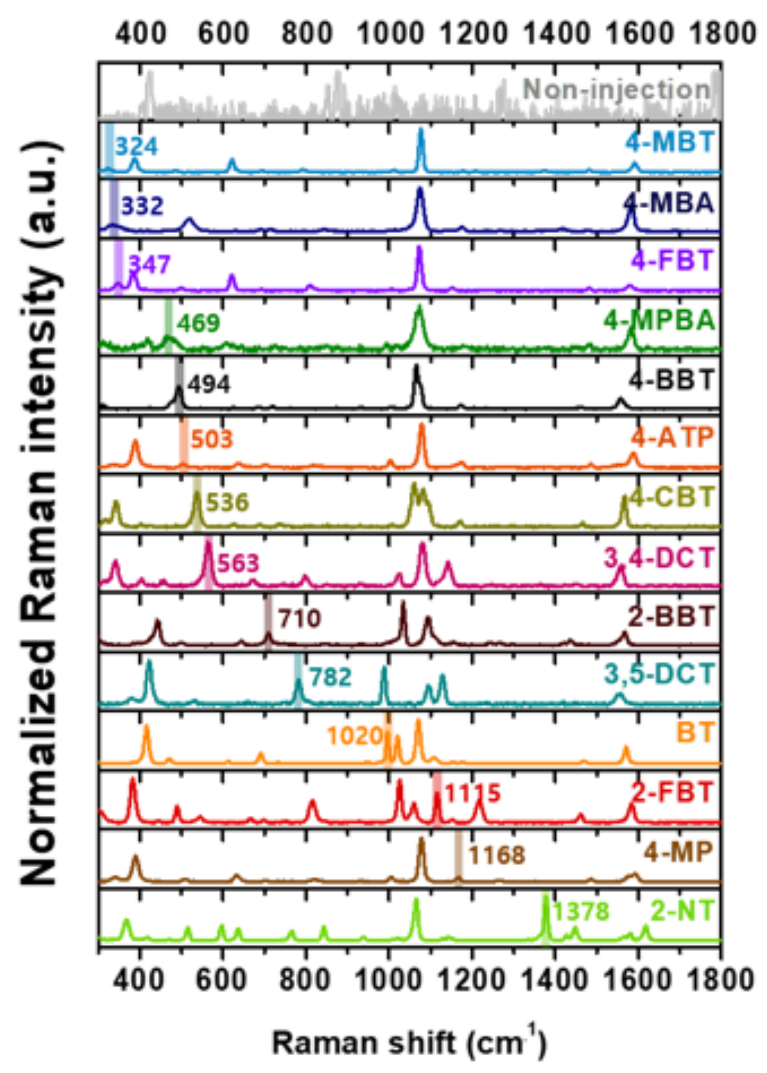

Figure 6

(a) Photograph of mouse injected with $\mathrm{SiO}_{2} @ A u @ \mathrm{Au}_{\mathrm{RLC}}$ with 14 Raman labeling compounds. (b) The 14 different normalized Raman spectra of $\mathrm{SiO}_{2} @ A u @ A u_{\mathrm{RLC}}$ injected into the nude mouse.

\section{Supplementary Files}

This is a list of supplementary files associated with this preprint. Click to download.

- Supportinginformation.docx

- Graphicalabstract.jpg 